\title{
Time course of priming for associate and inference words in a discourse context
}

\author{
ROBERT E. TILL \\ University of North Dakota, Grand Forks, North Dakota \\ and \\ ERNEST F. MROSS and WALTER KINTSCH \\ University of Colorado, Boulder, Colorado
}

\begin{abstract}
The construction of word meanings in a discourse context was conceptualized as a process of sense activation, sense selection, and sense elaboration. In three experiments, subjects read texts presented by a rapid serial visual procedure and performed a lexical decision on visually presented targets that followed ambiguous prime words. When the target was a word, it was either an associate of the prime word, a probable inference suggested by the discourse, or an unrelated word. For associates, lexical decisions that related to either the appropriate or the inappropriate sense of the ambiguous word were generally facilitated at short (200-400 msec) prime-target stimulus onset asynchronies (SOAs). At longer SOAs, responses were faster to appropriate than to inappropriate associates. For the thematic inferences, there was no difference between these (appropriate) inferences and (inappropriate) control words at short SOAs. At long SOAs (1,000 and $1,500 \mathrm{msec}$ ), however, inference words were facilitated. The results are interpreted as consistent with a model of lexical processing in which sense activation functions independently of context. Discourse context effects, whether on sense selection (suppression of inappropriate associates) or on sense elaboration (creation of inferences), are seen as postlexical.
\end{abstract}

Consider the following sentence pairs. How do we know what mint or interest means?

The townspeople were amazed to find that all the buildings had collapsed except the mint.

Thinking of the amount of garlic in his dinner, the guest asked for a mint.

The husband was afraid that his jealous wife would discover his new interest.

The millionare jumped from the window when he heard about the new rate of interest.

Surely more is involved than simply the activation of lexical nodes for mint and interest, although that must be part of it. Somehow, from whatever information is available in those lexical nodes, full contextual meanings of mint and interest must be constructed, taking into account the discourse context. In the present study, we explored the time course of these processes of word identification and meaning construction. Our principal goal was to inves-

This research was supported in part by Grant MH-15872-18 from the National Institute of Mental Health to Walter Kintsch. Experiment 1 was conducted at the University of Colorado while Robert Till was on sabbatical there. Experiments 2 and 3 were conducted at the University of North Dakota. We wish to thank Brad Benson, Elizabeth Hoffman, Jill Holden, Audrey O'Keefe, Steve Rambur, and Mark Sondreal for help with data collection, and Mark Grabe for comments on an earlier draft of the manuscript. Correspondence should be sent to Robert $\mathbf{E}$. Till, Department of Psychology, University of North Dakota, Grand Forks, ND 58202. tigate the effects of the discourse context on these processes.

More specifically, we were concerned with the changing nature of these effects in the course of discourse comprehension. With respect to lexical access, the question was whether the discourse context serves as some sort of filter that favors contextually appropriate meanings of a word over inappropriate ones, or whether the selection of the contextually appropriate word sense occurs only later in the process (e.g., when is the "candy" or the "money" sense of mint activated?). With respect to the process of generating full contextual meanings of words from the lexical materials that have been accessed, we wanted to know when discourse-based inferences are made that affect the discourse and, hence, the word meanings. In an appropriate context, for example, when does interest assume the meaning of "activity or hobby"? And when, again assuming the right context, does the fine tuning occur that yields the meaning "disapproved romantic activity that must be kept hidden, that is, an affair"? Similarly, what is the course of meaning construction for mint? When does mint assume the meaning of "the mint building," and when is it (more specifically) represented as "the strong, solid mint building in an earthquake"? Of course, many researchers have studied the ways in which words, whether lexically ambiguous or not, have different meanings depending on context, degree of semantic support, and subject strategies (e.g., Barclay, Bransford, Franks, McCarrell, \& Nitsch, 1974; Green- 
span, 1986; McKoon \& Ratcliff, 1986). Our focus in this study was on the time course of such meaning construction.

It has long been taken for granted that expectations based on the discourse context facilitate or inhibit the process of word identification: words that are expected are identified more rapidly and more accurately than words that do not fit into the discourse context. In recent years, some studies of priming effects in discourse contexts have challenged this conventional wisdom. In these priming experiments, subjects read or listen to discourse. At a certain point, a priming word is presented and followed by a secondary task. Typically, a letter string (the target) is presented visually, and subjects either decide as rapidly as they can whether the string forms an English word (lexical decision, as in Swinney, 1979) or name the word (naming, as in Seidenberg, Tanenhaus, Leiman, \& Bienkowski, 1982). Presentation of the text may be auditory (e.g., Swinney's, 1979, cross-modal priming) or visual (e.g., Kintsch \& Mross, 1985). Of interest is the reaction time to the target item in the lexical decision or naming task: if it is shortened relative to the reaction time to unrelated control words, the target is said to be primed by the prime word and/or the general discourse context. The results of these studies suggest to us that the general discourse context per se does not facilitate the identification of the target word, although associative relations between the prime and the target do.

We base this conclusion on two sets of observations. First, the context-appropriate and the contextinappropriate meanings of homographs are equally activated initially; discourse context merely serves to suppress the inappropriate meaning. This effect was first demonstrated by Swinney (1979) with a lexical decision task. It has since been replicated by Onifer and Swinney (1981) and by Kintsch and Mross (1985); see Simpson (1984) for a review. Confirming results were also obtained by Seidenberg et al. (1982) with a naming task. Second, words that are contextually appropriate but are not associatively related to the target word are not primed in either a lexical decision task (Kintsch \& Mross, 1985) or a naming task (Tanenhaus, Leiman, \& Seidenberg, 1979) in the initial stage of word identification. Thus, the discourse context neither inhibits the identification of inappropriate words nor facilitates the identification of appropriate words.

\section{Activation-Selection-Elaboration Model}

The results of these latter studies suggest that conceptions of word identification as a predictive process may be wrong. The discourse context does not appear to work as a filter that admits only the contextually appropriate, expected meaning of a word. Instead, word meanings appear to be accessed in a context-independent manner, but then to become successively more and more integrated into the discourse context. In other words, lexical access may be independent of context initially (Seidenberg et al., 1982; Tanenhaus et al., 1979), but it is followed by post- lexical integrative processes. Or, as Kintsch and Mross (1985) described it, a context-independent stage of sense activation is followed closely by the stages of sense selection and elaboration, thus shaping and indeed creating a contextually appropriate word sense.

In the sense activation phase, which appears to start within $\mathbf{5 0}$ msec after presentation (Fischler \& Goodman, 1978), all lexical meanings that correspond to a particular phonemic or graphemic input are activated. Presumably, discourse and situational contexts play no role in this activation process, but the relatively fixed associative and semantic relations within a person's lexicon do. Suppose, for example, that a subject reads the word mint as part of a discourse on earthquake damage to buildings. At this point, the two lexical nodes corresponding to the two meanings of mint are equally activated, and activation from either node spreads to a few neighboring, strongly associated nodes. "That is, both "candy" and "money" become activated. If either of these words is presented simultaneously or shortly after mint, priming effects are observed in lexical decision and naming tasks. After approximately $350-400 \mathrm{msec}$, the discourse context begins to select the appropriate meaning, or to suppress the inappropriate one. Priming is observed only for the contextappropriate associate "money," but no longer for "candy." This is the sense selection phase of word identification.

Even after the right sense of a word is selected, however, its meaning will be further elaborated contextually. It is probably not the case that fully developed word meanings reside somewhere in a lexicon, waiting to be selected and inserted into a discourse representation. Rather, the full contextual meaning of a word is likely to be constructed in the specific discourse context. Only such a generative, contextual view of meaning can do justice to the enormous flexibility and adaptability of human language (Kintsch, in press). The extent of contextual elaboration of a word's meaning, and the discourse in which it is embedded, depends upon one's view of what and how much information is contained in the mental lexicon. Resource availability, knowledge, and task demands play obvious roles in this elaboration process. It is the discourse meaning as a whole that is being elaborated, and word senses are affected by this elaboration because they are embedded in and part of that discourse meaning. Thus a sentence topic may be inferred and become part of the discourse representation, thereby affecting to some degree what each subsequent word means in this particular discourse context.

How well is such a view supported by the existing data? Although there are numerous demonstrations of context effects in word identification, they seem generally irrelevant to the present argument. The studies in question either do not deal specifically with only the sense activation process, or they fail to distinguish between the effects of "fixed" word associations and the effects of the discourse context per se. In support of the model, the equal priming of context-relevant and context-irrelevant associates 
of homophones and homographs appears to be established beyond reasonable doubt (Kintsch \& Mross, 1985; Onifer \& Swinney, 1981; Seidenberg et al., 1982; Swinney, 1979; Tanenhaus et al., 1979). On the other hand, there is less support for the claim that context-appropriate words, without any associative relations to the words in the text, are not primed initially. The problem is this: how does one determine what is context appropriate? Kintsch and Mross (1985), who found no evidence for priming of context-appropriate words, constructed short stories from the scriptal norms of Galambos (1982), omitting one important step in each story. For example, in a story about an executive catching a plane, one sentence described how he raced down the hallway and the next described how he got on the plane. The step "comes to the gate," which people expect between these two actions (according to the norms), was omitted from the story. Hence, it could be argued that "gate" was a contextually appropriate word, at that point, and a good canditate for contextual priming. Although this seems a reasonable argument, Kintsch and Mross did not actually show that at this particular point in their story, readers made an inference such as "he passes the gate."

The present experiments were designed to further explore the time course of word identification and meaning elaboration in discourse. There were two major concerns in these experiments, one with associates of the priming words, the other with discourse-based inferences.

In each experiment, we manipulated the degree to which a priming word was processed and observed the effects on both context-appropriate and context-inappropriate associates. For the most part, these data are replications of results already reported in the literature, except that we explored the time course of processing in more detail, from 200 to 1,500 msec. In Experiments 1 and 2, we were concerned only with the difference in priming between context-appropriate and context-inappropriate associates. The goal was to trace out the time course of sense selection. In Experiment 3, associates were contrasted with unrelated control words in an effort to demonstrate evidence for multiple access at the sense activation stage.

The second question concerned the time course of meaning elaboration. Specifically, we investigated when topical inferences are made or are demonstrable given the special task demands and conditions of the present experiments. We assumed that if readers were encouraged, and were given enough time, they would make the invited topic inferences for our experimental materials. Are these inferences made as a sentence is being read, as soon as they become computationally possible, as some versions of the immediacy hypothesis (Just \& Carpenter, 1980) suggest? Or is this kind of elaboration of the discourse meaning part of the sentence wrap-up? We were not concerned here with mapping the time course of strategic processing of inferences over the course of our unfolding stories, although in pilot work we found no reliable inference priming at the earlier points in the discourse that we chose to examine. ${ }^{2}$ Rather, we were concerned to show that inferences known to be computable at a certain locus are not primed initially (at less than a 1,000-msec SOA).

\section{EXPERIMENT 1}

In Experiment 1, subjects read brief texts, presented one word at a time. Each contained a homograph whose meaning was unambiguously specified by the context. Text presentation was interrupted, immediately following the homograph, with a lexical decision trial. There were five kinds of target items: nonword targets, contextually appropriate associates of the prime, contextually inappropriate associates, appropriate inference words (high-probability inferences from the text), and inference control words (words that were actually appropriate inferences for other texts). Stimulus onset asynchrony (SOA), between the onset of the prime and the onset of the target, was $333 \mathrm{msec}$ or $1,000 \mathrm{msec}$. Targets presented at the short SOA presumably came at the end of the sense activation phase, or perhaps at the beginning of the sense selection phase. Thus, we expected little or no effect of discourse context. At the short SOA, we expected response latencies for both associates to be comparable, and the latencies for the inference words and inference control words to be comparable. At the long prime-target SOA, in contrast, we expected context effects for both associate and inference words. That is, we expected appropriate associates to be primed relative to inappropriate associates, and appropriate inference words also to be primed relative to the (inappropriate) inference control words. In sum, for both associate and inference targets, we expected an interaction between primetarget SOA and contextual appropriateness, with appropriateness having an effect only at the longer SOA interval.

\section{Method}

Subjects. The subjects were 48 undergraduates from the University of Colorado who participated to fulfill a psychology course requirement. The subjects were randomly assigned to the two prime-target SOA conditions, with 24 in each group.

Design. The between-subjects variable was prime-target SOA, with subjects in either the 333-msec or the 1,000 -msec condition. Two within-subject variables resulted from the crossing of context appropriateness and target type. Of 56 critical target words requiring a positive lexical decision, 14 were appropriate associates, 14 were inappropriate associates, 14 were appropriate inferences, and 14 were inference control words (i.e., "inappropriate inferences," since there was no obvious relation between primes and target words). Although not analyzed, list was treated as a design variable and was counterbalanced across subjects. Half the subjects saw the texts of List A first, followed by List B, and half saw the lists in the other order.

Materials. Two lists were constructed, each with 28 critical paragraphs and 21 filler paragraphs. Critical paragraphs were those in which a priming word was followed by a test item that was an English word, rather than a nonword. Only one such test item was presented in each paragraph. The critical paragraphs and test words are shown in Appendix A.

The two lists were constructed in parallel. Specifically, a pair of paragraphs was written around an ambiguous noun that appeared in both. Story content and inferences were adapted from materials used previously in cued recall experiments (Till, 1977; Till \& Walsh, 
1980). The ambiguous item was used as the priming word for the lexical decision test item that interrupted the story. Paragraph pairs were constructed so that only one meaning of the ambiguous word was appropriate for each paragraph in a pair. Each paragraph consisted of two sentences and was about 22 words in length. For approximately half of the paragraphs in each list, the ambiguous word appeared in the first sentence, and for the other half, it appeared in the second sentence.

The ambiguous nouns were selected from Cramer's (1970) association norms for homographs. As much as possible, the homographs (which were also homophones) were chosen such that among their top associates there was a pair of approximately equally strong associations to both senses of the word. For example, iron was selected because its two strongest associates are "steel," with a response probability of .128 , and "clothes," with a response probability of .119. The ambiguous noun always appeared at the end of a sentence, but we constructed sentences so that endings were not predictable (i.e., $80 \%$ of the sentences would have been grammatical had they ended at some point before the ambiguous word).

For each ambiguous word used in the critical paragraphs, the two paragraphs containing it were assigned to List A or List B so as to keep the average prime/test word associative strength approximately equal for the two lists. Critical paragraphs were also constructed so that certain probable inferences might be drawn during comprehension. Thus, the paragraphs in a pair were worded to suggest not only different associates to the prime word, but also different inferences, of approximately equal response strength. The initial assignment of paragraphs in each pair to Lists $\mathrm{A}$ and $\mathrm{B}$, equating the lists for associative strength of associate test words, was modified to ensure that the "inference strength" of inference test words was also approximately equal for List A and List B.

The inference words chosen to be test words rarely or never appeared in Cramer's (1970) association norms. Typically, they were modal responses of moderate strength made by 62 subjects asked, in a pilot study, to read each paragraph up to the point of the prime word, and to write down a word reflecting their understanding of what the paragraph was about. An examination of the inference word responses showed that our previously selected associate test words rarely appeared as inference responses.

Characteristics of the test words used in critical paragraphs are summarized in Table 1. The data are collapsed over Lists A and $B$, which were constructed to be quite similar on these values. In response to an associate priming word, our associates were often given (.159), whereas our inference words rarely occurred (.001). In response to our story contexts, the (appropriate) inference words were frequently given (.242), whereas the (appropriate) associates rarely appeared (.025). It is also apparent in Table 1 that associates were generally shorter than inference words $[t(55)=3.87$, $p<.001]$, but were not significantly higher in mean word frequency $[t(55)=1.42]$; however, a simple sign test, insensitive to the skewness, suggested that associates were of higher word frequency: for 38 of 56 pairs, $p<.05$.

The 28 critical paragraph pairs were divided into four subgroups that were as similar as possible on the characteristics noted above. These subgroups were assigned to the four test-word conditions (appropriate associate, inappropriate inference, etc.) according to a Latin square arrangement. Thus, each subgroup of paragraphs was tested equally often in each test-word condition. Specifically, there were 6 subjects in each of four subgroup-assignment conditions.

Since all subjects saw List A and List B, they necessarily encountered each prime word twice. Therefore, assignment of test words to subgroups of paragraphs was constrained such that test words during the second list were different in type and appropriateness. For example, if a paragraph from the first list was tested with an appropriate associate, then the corresponding paragraph in the second list was tested with an inappropriate inference control word. Similarly, when the first list used an inappropriate associate, the corresponding item in the second list used an appropriate inference.

The 21 filler paragraph pairs, containing the negative (i.e., nonword) lexical decision trials, were of similar style and word length. They were written around an ambiguous noun, from Cramer's (1970) norms, not used in preparing the critical paragraphs. Each paragraph consisted of two sentences, with the ambiguous noun placed at the end of the first or second, and was written to suggest some kind of thematic inference. The nonword targets were taken from Taft (1982). Since filler paragraphs were used only for negative trials, we made no attempt to quantify associative or inference strength. One filler paragraph from each pair was arbitrarily assigned to List $\mathbf{A}$ and List $\mathbf{B}$.

Within each list, the 28 critical paragraphs were combined with the 21 filler paragraphs such that every block of 7 paragraphs contained a random ordering of the following trials: one appropriate associate, one inappropriate associate, one appropriate inference, one inference control word, and three nonword test items. The random orderings for List A and List B were unrelated. An example of a block of 7 paragraphs from List $A$ is shown in Table 2; all possible test words are shown along with the (italic) test words for 1 subject.

For each list, we constructed 14 comprehension items. Each was a single sentence requiring a "yes" response if it was a true (though perhaps abbreviated) statement from an earlier paragraph or a "no" response if it was a scrambling of earlier paragraphs (subjects and predicates from different paragraphs). After every block of seven paragraphs, 2 comprehension items based on that block were presented. Comprehension items were presented 1 at a time. Half of the items called for a "yes" response, and half called for a "no."

Table 1

Characteristics of Test Words

\begin{tabular}{lccccc}
\hline & & & \multicolumn{2}{c}{ Response Probability in Context } \\
\cline { 5 - 6 } Test Word & $\begin{array}{c}\text { Number } \\
\text { \& Measure }\end{array}$ & $\begin{array}{c}\text { Word } \\
\text { Syllables }\end{array}$ & $\begin{array}{c}\text { Frequency } \\
\text { Associative }\end{array}$ & $\begin{array}{l}\text { Sentence Context } \\
\text { Prime Only }\end{array}$ & $\begin{array}{l}\text { Appropriate } \\
\text { Inappropriate }\end{array}$ \\
\hline Associates & & & & & \\
$M$ & 1.28 & 158.6 & .159 & .025 & $.001^{*}$ \\
$S D$ & .56 & 217.1 & .102 & .046 & .002 \\
Inferences & & & & & \\
$M$ & 1.71 & 89.6 & $.001^{*}$ & .242 & 0 \\
$S D$ & .73 & 280.1 & .002 & .165 & 0 \\
\hline
\end{tabular}

Note-All means were based on 56 observations. Word length for associates and inferences differed, as did word frequency (from Kucera \& Francis, 1967, norms), once the effect of skewness was removed. Median word frequency for associates was 89.5 and for inferences was 30.5 . Response probabilities for associations to prime words were taken from Cramer's (1970) norms. Response probabilities for inferences to story contexts were based on normative pilot data of the present study. *Actual probability was less than .001 . 
Table 2

Sample of Paragraphs, Target Items, and Comprehension Items Taken from List A

\begin{tabular}{|c|c|c|c|c|c|}
\hline \multirow[b]{3}{*}{ Paragraphs } & \multirow[b]{3}{*}{ Nonword } & \multicolumn{4}{|c|}{ Possible Target Items } \\
\hline & & \multicolumn{2}{|c|}{ Associate } & \multicolumn{2}{|c|}{ Inference } \\
\hline & & Appropriate & Inappropriate & Appropriate & Inappropriate \\
\hline $\begin{array}{l}\text { The stewardess was really looking forward to } \\
\text { going on a vacation in the spring *** That's } \\
\text { when the skiing is best. }\end{array}$ & duve & & & & \\
\hline $\begin{array}{l}\text { The old man sat with his head down and did no } \\
\text { hear a word of the sermon during mass *** } \\
\text { Nevertheless, he felt better after the service. }\end{array}$ & & church & weight & sleep & test \\
\hline $\begin{array}{l}\text { The millionaire jumped from the window when } \\
\text { he heard about the new rate of interest } * * * \\
\text { His entire fortune was at stake. }\end{array}$ & & money & hobby & suicide & affair \\
\hline $\begin{array}{l}\text { The jogger had been running at a quick pace bu } \\
\text { did not feel winded. Then all of a sudden, he } \\
\text { felt a muscle tighten in his calf } * * *\end{array}$ & flud & & & & \\
\hline $\begin{array}{l}\text { The townspeople were amazed to find that all } \\
\text { the buildings had collapsed except the mint } \\
\text { *** Obviously, it had been built to withstand } \\
\text { natural disasters. }\end{array}$ & & money & candy & earthquake & breath \\
\hline $\begin{array}{l}\text { The audience stood and continued to clap loudly } \\
\text { after the last refrain *** The performance was } \\
\text { easily the best of the concert season. }\end{array}$ & & song & stop & encore & gamble \\
\hline $\begin{array}{l}\text { The two brothers decided to go fishing for bass } \\
\text { on the lake. Unfortunately, all they caught } \\
\text { was perch *** }\end{array}$ & sware & & & & \\
\hline Comprehension Items & & & Correct & ponse & \\
\hline $\begin{array}{l}\text { The townspeople had been running at a quick } \\
\text { pace. }\end{array}$ & & & & & \\
\hline $\begin{array}{l}\text { The millionaire heard that all the buildings had } \\
\text { collapsed except the mint. }\end{array}$ & & & & & \\
\hline
\end{tabular}

Finally, we prepared a single set of seven paragraphs and two comprehension items for use as practice material. These items were similar in style and length to the experimental materials.

Procedure. Upon arrival, a subject was randomly assigned to one of two prime-target SOA conditions (333 or 1,000 msec) and then to one of the 8 combinations of 2 list orders $\times 4$ subgroupassignment orders.

The subjects worked individually on IBM PCs equipped for realtime experiments, with up to 2 subjects in the same experimental room. They were instructed to read the stories that would be presented in the center of the screen, by means of a rapid serial visual procedure (RSVP), and to be prepared to answer later questions about the stories. A 2-sec fixation point (asterisk) occurred first, followed by a 1-sec pause, and then the first word of a story. During the text presentation, the words followed each other on the same central screen location, each word being presented for $333 \mathrm{msec}$ (with negligible off-time between words).

In addition to reading for comprehension, the subjects were asked to perform a second task as fast as possible and without errors: Once in each story paragraph, a target string appeared in the center of the screen, and the subjects' task was to indicate whether the letters formed an English word by pressing a key identified as "yes" or one identified as "no." Index fingers were to be kept on these keys at all times. These lexical decision trials clearly interrupted the reading of the paragraph since the target string appeared in the same location as previous words, but was flanked by four asterisks (e.g., **** clothes****).

In the 333-msec condition, these target strings occurred immediately after the ambiguous prime word (i.e., with the same latency as all other words in the text). In the 1,000 -msec condition, target strings appeared $667 \mathrm{msec}$ after the offset of the prime word. Presentation of a target string started a timer that recorded response latency; the actual response ("yes" or "'no") was also recorded. Text presentation resumed when the subject made the response, or when $2,000 \mathrm{msec}$ had elapsed (in which case the trial was counted as an error). There was a $2-s e c$ pause between texts.

After the instructions, the subjects read a series of seven practice stories, each containing a lexical decision trial, followed by two comprehension items requiring a yes/no (untimed) response. Each comprehension item remained on the screen until a "yes" or "no" response was made.

All subjects appeared to understand the comprehension and lexical decision tasks by the end of the practice session. The first list of paragraphs and comprehension items then was presented just as in the practice trials except that, after every block of seven texts and two comprehension items, the subjects controlled the initiation of the next block with a keypress. After the first list, the subjects had a brief, self-paced rest pause. Without further instruction, the subjects then worked through the materials of the second list just as they had the first. 


\section{Results}

Comprehension scores were high $(M=88 \%)$ and lexical decision errors were few, suggesting that the subjects had complied with the instructions that emphasized the importance of both tasks. The overall error rate for positive lexical decision trials was $3.8 \%$, with $0.6 \%$ due to response latencies exceeding $2,000 \mathrm{msec}$. The specific error rate associated with each type of target word varied from $0.6 \%$ to $3.6 \%$, but there was no significant difference between the two SOA conditions $[t(46)=0]$ and no evidence of a speed-accuracy trade-off. Similarly, there was no significant difference between SOA conditions in comprehension scores $[t(46)=1.12]$.

The major analyses were based on the latencies of correct lexical decisions. The median latencies for each subject in each condition (appropriate associates, inappropriate associates, inferences, and inference controls) constituted the basic data. These medians were based on up to 14 items. A significance level of .05 was used.

Two separate analyses are reported here. First, an analysis of variance (ANOVA) corresponding to the experimental design was performed to obtain an overall view of the data. Only an analysis with subjects as the unit is reported because there are insufficient data to treat items as the unit in Experiments 2 and 3. Although this limits the statistical generalizability of our results to the item pool used here, the experimental design itself controls for materials effects: texts as well as targets were counterbalanced across the appropriate and inappropriate contexts. In the second analysis, the predictions made by the activation-selection-elaboration theory were tested more directly by orthogonal contrasts, separately for associates and inferences. In this analysis, we do not use the orthogonal comparisons for the purpose of exploring an ANOVA result, but rather we partition the betweenconditions sum of squares in the way suggested by the theory.

Mean response times are shown in Figure 1 as a function of the prime-target SOA, item type, and context appropriateness. A preliminary check on variances associated with each mean showed no significant departure from homogeneity of variance $\left[F_{\max }(8,23)=1.76\right]$. According to the activation-selection-elaboration model, context appropriateness should not matter for either associates or inferences at the short prime-target intervals, but response times should be shorter for contextappropriate inferences and associates at longer prime-target intervals. This is the result that was obtained.

Overall ANOVA. The two prime-target SOAs of 333 and 1,000 msec constituted the between-subjects factor in the analysis, whereas item type (inferences/associates) and appropriateness (appropriate/inappropriate) were within-subject factors. Responses following the longer SOA were significantly faster than responses following the shorter SOA $[F(1,46)=3.91, M S e=62,689.0]$, which probably reflects a preparation effect: the blank screen helped subjects to prepare for the lexical decision response. Furthermore, responses to associates were sig- nificantly faster than responses to inferences $[F(1,46)=$ $12.40, M S e=2,921.9]$; since these two groups of words differed in various ways, this is not a particularly interesting result. The third main effect in the analysis, context appropriateness, was not significant. The only interaction in the analysis that reached the level of significance was the interaction between prime-target SOA and appropriateness $[F(1,46)=6.65, M S \mathrm{e}=3,719.4]$. This interaction was predicted by the theory: at the shorter SOA, the discourse context had not yet had enough time either to deactivate the inappropriate associate or to activate the appropriate inference, whereas both of these processes had been completed by the longer, full-second SOA.

Theoretical predictions. A direct test of the predictions made by the activation-selection-elaboration model was possible by examining appropriateness differences at each prime-target SOA by means of orthogonal comparisons. At the 333-msec SOA, there were no appropriateness differences either for associates or for inferences (both $F<1$ ); but at the 1,000-msec SOA, latencies for context-appropriate associates were faster than for inappropriate associates $[F(1,46)=13.74]$, and latencies for inference words were faster than for inference control words $[F(1,46)=23.01]$.

The results of Experiment 1, therefore, are in agreement with the experimental predictions. However, they leave a number of questions unanswered. We have argued that the lack of a difference between appropriate and inappropriate associates at the $333-\mathrm{msec}$ SOA reflects the fact that both are primed at this point in time, that is, primed relative to unrelated control words (not actually included in this experiment). Although this argument is amply supported in the literature, the present data do not speak to it (i.e., a direct comparison between associates and inference controls is vitiated by uncontrolled item differences), and we take up this matter again in Experiment 3. In Experiment 2, we explored the time course of priming over a wider range of prime-target SOAs.

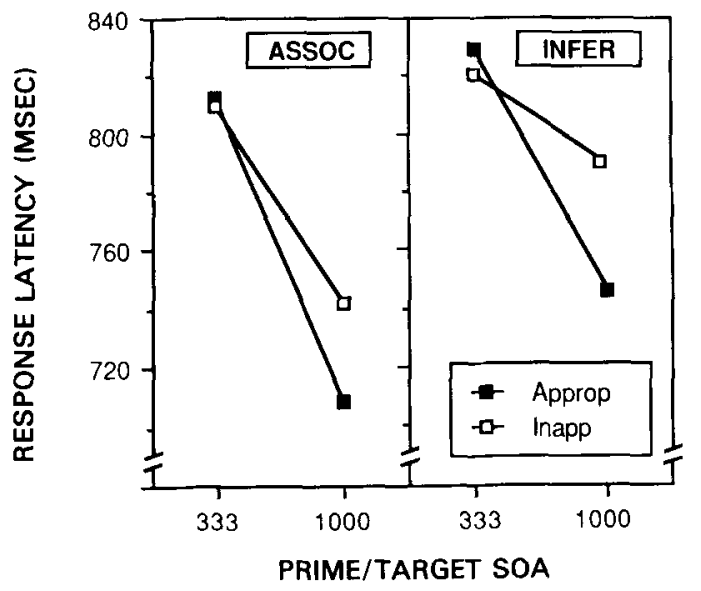

Figure 1. Response latencies on positive lexical decision trials for associate and inference words in Experiment 1. Data are shown for prime-target onset asynchronies of $333 \mathrm{msec}$ and $1,000 \mathrm{msec}$ and as a function of context appropriateness. 


\section{EXPERIMENT 2}

A second experiment was performed in an attempt to replicate our findings and to explore in more detail the time course of priming for associate and inference words. Six prime-target SOA intervals were included: 200,300 , $400,500,1,000$, and 1,500 msec. Most details of the method were identical to those of Experiment 1, except where noted. By testing several SOA intervals, we hoped to observe any differences in the time course of context effects on associate and inference words.

\section{Method}

Subjects. The subjects were 102 undergraduates from the University of North Dakota who participated for course credit. The data from 6 subjects were discarded because of failure to understand the task ( 1 case), lexical decision error rates more than three standard deviations above the group mean ( 2 cases), or comprehension scores more than three standard deviations below the group mean ( 3 cases). The subjects were randomly assigned to six groups, with 16 in each.

Design and materials. The design and materials were the same as in Experiment 1, except that there were six prime-target SOA conditions $(200,300,400,500,1,000$, and $1,500 \mathrm{msec})$. In addition to list order, paragraph order was treated as a design variable and counterbalanced across subjects. Thus, in contrast to Experiment 1 , half of the subjects seeing a given list saw the paragraphs in one order (forward order), and the other half of the subjects saw them in the opposite order (reverse order).

Procedure. Upon arrival, a subject was randomly assigned to one of six SOA conditions, and then further assigned to one of 16 combinations of 2 list orders $\times 2$ paragraph orders $\times 4$ (materials) subgroup-assignment orders.

The subjects were tested individually as they sat in front of an Apple Ile computer; only 1 subject was tested at a time. Text presentation was the same as in Experiment 1, except that all words appeared on the screen for $300 \mathrm{msec}$. Thus, in the $300-\mathrm{msec}$ condi- tion, target strings occurred immediately after the prime word, and the story reading rate and prime-target SOA were the same. In the 500 - and 1,500-msec conditions, in contrast, target strings appeared 200 and $1,200 \mathrm{msec}$, respectively, after the offset of the prime word. Of course, in the 200-msec condition, target strings appeared immediately after a somewhat shortened $(200-\mathrm{msec})$ exposure of the prime word. In contrast to Experiment 1, response latencies were recorded even if they exceeded $2,000 \mathrm{msec}$.

\section{Results}

Comprehension scores were high $(M=90 \%)$, and the overall error rate for positive lexical decision trials was low $(M=2.4 \%)$. The six SOA groups were not significantly different on comprehension scores $(F<1)$ or on error rates $(F<1)$. The specific error rate associated with each type of target word varied somewhat, from $0.4 \%$ to $6.2 \%$. As in Experiment 1, however, the major analyses were based on response latencies for correct lexical decision trials. Latencies above $2,000 \mathrm{msec}$ were quite rare (less than .3\% of all cases), and in no case did they affect the magnitude of computed median latencies.

The mean response times for both inferences and associates are shown in Figure $2{ }^{3}$ A preliminary check on the variances associated with these means supported the assumption of homogeneity of variance $\left[F_{\max }(24,15)=\right.$ 5.31]. From the figure, it appears that context does not facilitate lexical decisions for inference words at brief prime-target SOAs. However, latencies for the 1,000- and 1,500 -msec conditions suggest that responses to inference words are faster than responses to inference control words. The picture is less clear for associates, for which there appears to be a context effect at all prime-target SOAs. We note, however, that this effect is small at prime-target SOAs of 200 and $300 \mathrm{msec}$ but considerably larger for SOAs of $400 \mathrm{msec}$ or more.

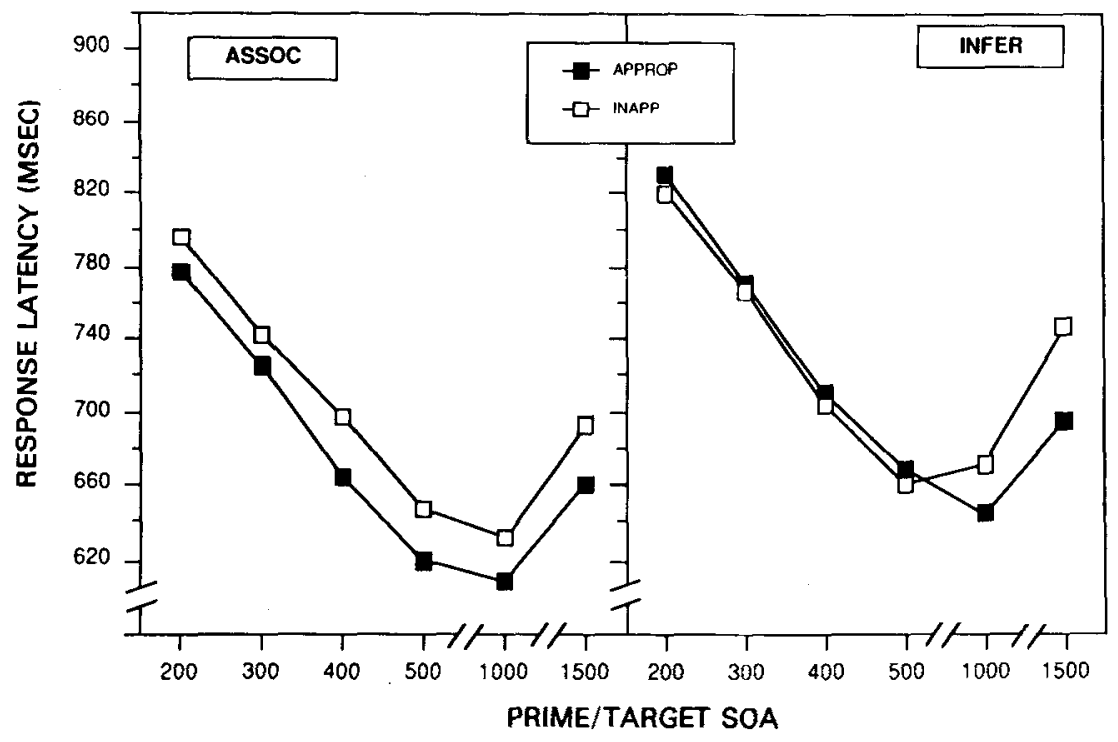

Figure 2. Response latencies on positive lexical decision trials for associate and inference words in Experiment 2. Data are shown for prime-target onset asynchronies of $\mathbf{2 0 0}, \mathbf{3 0 0}$, $400,500,1,000$ and 1,500 msec, and as a function of context appropriateness. 
Overall ANOVA. This analysis was similar to that of Experiment 1, except that there were six prime-target SOAs rather than two. All three main effects were statistically significant. Lexical decision times decreased as the prime-target SOA increased $[F(5,90)=4.53, M S e=$ $56,985.6]$, but only up to $1 \mathrm{sec}$, after which this trend reversed. Presumably, long preparation intervals are not optimal. Context-appropriate words were responded to faster than inappropriate words $[F(1,90)=13.23, \mathrm{MSe}$ $=1,979.9$ ]. Latencies for associates were faster than for inferences $[F(1,90)=51.92, M S e=2,322.8]$. Furthermore, the item type $\times$ appropriateness interaction reached significance $[F(1,90)=5.60, M S e=1,171.8]$. These effects are evident in Figure 2, but they are not of particular interest theoretically. The theory predicts either an SOA $\times$ appropriateness interaction (i.e., no context effects at short SOAs, and appropriate associates and inferences faster than inappropriate ones at long SOAs) or a triple interaction with item type (i.e., context effects should appear earlier for associates than for inferences since sense selection normally precedes elaboration). However, neither of these interactions was significant $[F(5,90)=1.70, p=.14$, and $F(5,90)=1.90, p=.10$, respectively]. Thus, the ANOVA results do not provide clear support for the theory. Alternatively, this failure represents a lack of power rather than a disconfirmation of the theoretical predictions: the trends in Figure 2 are quite what was expected. Since interactions based on several degrees of freedom do not provide a very sensitive test of the theoretically important issues, we turn again to a more powerful test-orthogonal comparisons of the theoretically relevant differences.

Theoretical predictions. The difference between context-appropriate inferences and inference control words was tested separately for each prime-target SOA by means of orthogonal comparisons. The $F$ values obtained for these tests at the 200-, 300-, 400-, and 500msec SOAs were all less than 1 , whereas for the 1,000 and 1,500-msec SOAs, context effects were significant statistically $[F(1,90)=4.61$ and $F(1,90)=19.17$, respectively].

For associates, the discourse context did not have a significant effect at the two shortest prime-target SOAs $[F(1,90)=2.26$ and $F(1,90)=2.02$, respectively $]$. In contrast, context-appropriate associates were significantly facilitated relative to inappropriate associates at 400,500 , and $1,500 \mathrm{msec}$, with $F$ values of $4.45,4.32$, and 4.62 , respectively. For the 1,000 -msec SOA, the context effect just missed the significance level $[F(1,90)=3.65$, $p=.06]$.

Thus, the results of the orthogonal comparisons are in general agreement with the predictions of the activationselection-elaboration theory, and replicate the findings of Experiment 1. At the shortest prime-target SOA, processing is still in the sense activation phase, and there are no statistically reliable context effects, either for inferences (relative to control words) or for appropriate associates (relative to inappropriate associates). Between 300 and 400 msec, a difference appears to develop between appropriate and inappropriate associates: that is, sense selection has probably occurred by this time. Still more time is required, however, for sense elaboration: thematic inferences are not made until after $500 \mathrm{msec}$, but before $1,000 \mathrm{msec}$. Experiment 2 thus provides a more detailed examination of how the effects of the discourse context develop during discourse comprehension, although the lack of a statistically significant interaction effect in the analysis of variance raises some question about the reliability of these results. We return to this question in the General Discussion. Experiment 3 clarified another aspect of the activation-selection-elaboration process.

\section{EXPERIMENT 3}

In the previous two experiments, the discourse context appeared not to have significant effects on the process of word identification at the shortest prime-target SOAs. According to the activation-selection-elaboration model, this was so because at that early point in the processing, both context-appropriate and context-inappropriate associates were activated relative to unrelated control words, whereas neither the appropriate inferences nor their inference controls were as yet activated. The second part of this claim is directly supported by the results of Experiments 1 and 2: at intervals up to $500 \mathrm{msec}$, lexical decisions to thematic inference words were no faster than lexical decisions to control words that were unrelated to the discourse context. Experiments 1 and 2 were not designed, however, to provide evidence with regard to the first point: that both discourse-appropriate and -inappropriate associates of a priming word are activated at brief prime-target intervals and that, hence, both are facilitated relative to unrelated control words. Of course, there have been numerous demonstrations in the literature relative to this point, since Swinney's (1979) original work. Nevertheless, it would be desirable to demonstrate that this holds also for the present set of materials.

In Experiment 3, therefore, we examined associate words at prime-target SOAs of 200 and $300 \mathrm{msec}$, comparing them with suitable control words. The purpose was to replicate once more the Swinney (1979) result that appropriate and inappropriate associates are equally activated at this stage in the process of word identification. The experiment also provided a check on those results of Experiment 2 that were somewhat ambiguous: the slight, nonsignificant context effect for associates at these prime-target SOAs, which probably contributed to the failure of the SOA $x$ appropriateness interaction to reach the conventional level of statistical significance.

Specifically, Experiment 3 was designed to examine only associate words at prime-target SOAs of 200 and $300 \mathrm{msec}$. Within each complete list of 56 critical paragraphs, the 28 inference words were removed and replaced with the 28 associate words not used in this list. Thus, each subject saw 14 appropriate associates, 14 inappropriate associates, and 28 control words irrele- 
vant to the paragraph content, but matched in frequency and word length with the associate targets.

\section{Method}

Subjects. The subjects were 35 undergraduates from the University of North Dakota who participated for course credit. The data from 3 subjects were discarded because of comprehension scores more than three standard deviations below the group mean ( 2 cases) or lexical decision error rates more than three standard deviations above the group mean ( 1 case). The subjects were randomly assigned to the two groups, with 16 in each.

Design and materials. The design and materials were similar to those of Experiment 2, except that there were only two prime-target SOA conditions ( 200 and $300 \mathrm{msec}$ ). Furthermore, we used only one paragraph order, as was done in Experiment 1.

Most important, the materials were altered so that for every point at which an inference target word appeared, an unused associate word was substituted. These substitutions were done randomly, except for the constraint that the substituted word could not be related to either the appropriate or inappropriate sense of the ambiguous prime preceding it.

Procedure. Instructions and procedures were identical to those of Experiment 2.

\section{Results}

Comprehension scores were high $(M=86 \%)$, and the overall error rate for correct lexical decision trials was low $(M=2.2 \%)$. The two SOA conditions did not differsignificantly on either measure (both $t s<1$ ), nor were they different from the averages of the corresponding measures from Experiment 2 (again, both $t$ s $<1$ ).

Figure 3 presents the mean latencies of the lexical decisions for appropriate and inappropriate associates and control words. As before, we found evidence for homogeneity of variances $\left[F_{\max }(6,15)=1.57\right]$. Two results, apparent in the figure, are of interest: the discourse-irrelevant control words have longer reaction times than either the context-appropriate or contextinappropriate associates, and there is no real difference between the latter two groups of words.

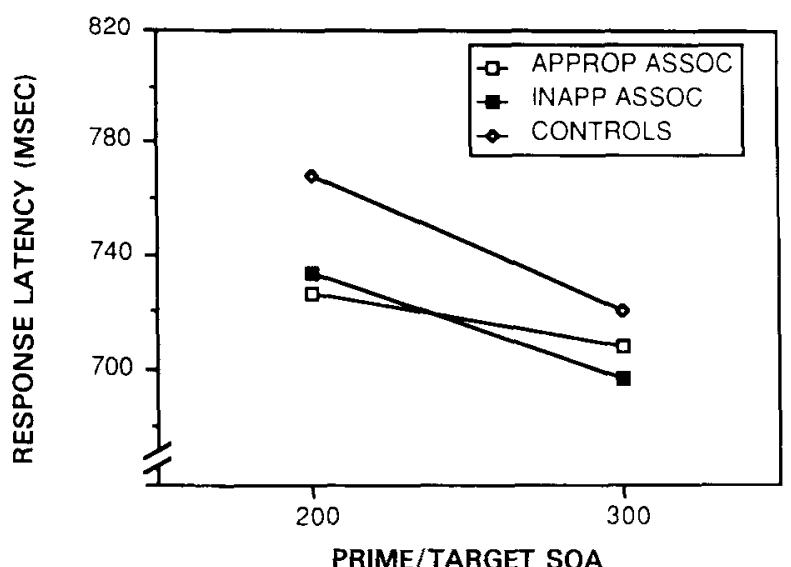

Figure 3. Response latencies on positive lexical decision trials for associate test words in Experiment 3. Data are shown for prime-target onset asynchronies of 200 and 300 msec, for contextappropriate associates, context-inappropriate associates, and matched control words.
Overall ANOVA. Mean latencies were analyzed in an ANOVA with the between-subject factor of prime-target SOA (200 and $300 \mathrm{msec}$ ) and the within-subject factor of item type (appropriate associates, inappropriate associates, and controls). The main effect of item type was statistically reliable $[F(2,60)=8.00, M S e=1,041.2]$, but neither the main effect of prime-target SOA $[F(1,30)$ $=0.50]$ nor the SOA $\times$ item type interaction $[F(2,60)$ $=1.64]$ was significant.

Theoretical predictions. Orthogonal comparisons revealed that the difference between appropriate and inappropriate associates was not significant at either the 200or the 300-msec SOA (both $F \mathrm{~s}<1$ ). The difference between the control words and the average of the two types of associates was significant at the $200-\mathrm{msec}$ SOA, $[F(1,60)=4.43]$, although it just missed significance at the 300 -msec SOA $[F(1,60)=3.51, p=.06]$.

Experiment 3 can be regarded as another successful replication of Swinney's (1979) result that associates of a priming word are equally facilitated in a lexical decision task, whether or not they are appropriate to the discourse context-at least for the first $300 \mathrm{msec}$ of processing, and as long as the associates are symmetric in the sense of being equally related to both senses of the priming word.

\section{GENERAL DISCUSSION}

The three experiments reported here, taken jointly and in conjunction with other results in the literature, provide considerable support for the activation-selection-elaboration model of word identification and meaning construction in a discourse context. The data are summarized in Figure 4, which shows, for each prime-target SOA, the discourse context effect: mean reaction times for inappropriate associates (or, alternatively, inference controls) minus appropriate associates (or appropriate inferences). In Figure 4, a star above a bar indicates a difference large enough to be significant in the orthogonal comparisons analysis.

The picture that emerges when the three experiments are put together in this way is quite consistent. Inference words are not activated by the discourse context, and hence are not facilitated in a lexical decision task, until the priming word has been processed for more than $500 \mathrm{msec}$; this observation replicates the main result of Kintsch and Mross (1985), and is consistent with the data of Seidenberg et al. (1982) and Tanenhaus et al. (1979). At longer prime-target intervals, however, thematic inference words are strongly facilitated relative to unrelated control words. Sense elaboration, under the present experimental conditions, appears to require more than $500 \mathrm{msec}$.

Sense activation, however, is achieved within $400 \mathrm{msec}$ : after processing has reached that stage, discourseappropriate associates are generally facilitated relative to inappropriate associates. Similar results have been reported by Onifer and Swinney (1981), Seidenberg et al. (1982), 


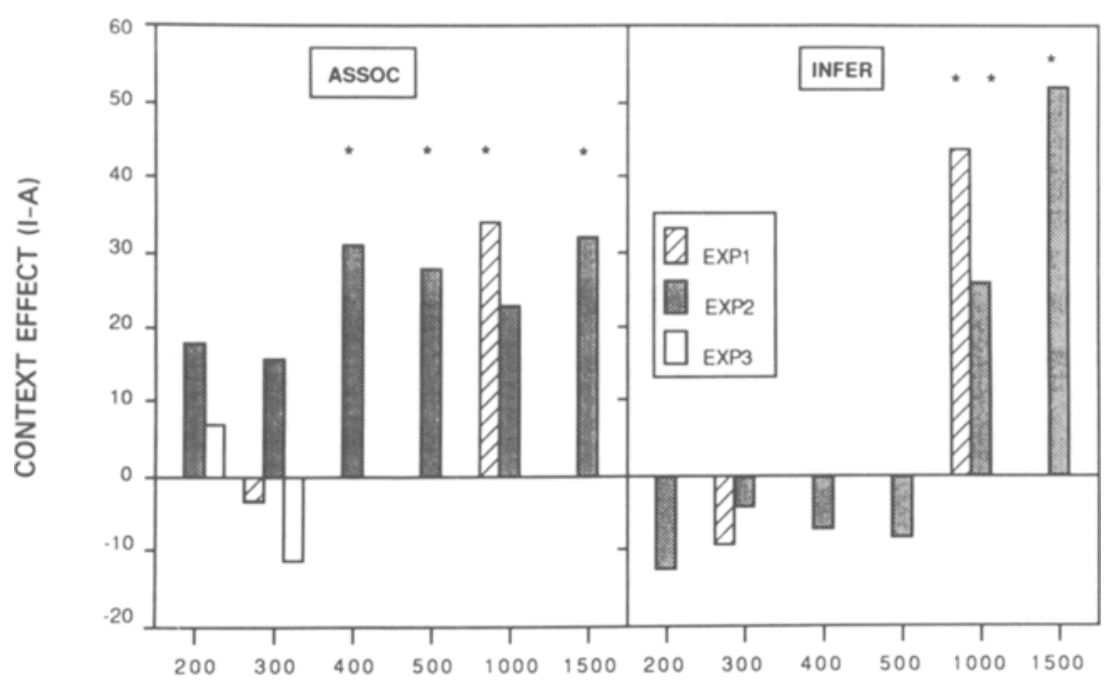

PRIME-TARGET ASYNCHRONY (IN MSEC)

Figure 4. Contextual priming for associates and inferences as a function of the prime-target asynchrony in Experiments 1-3. The bars represent the magnitude of observed priming: response latencies for inappropriate associates (or inference controls) minus response latencies for appropriate associates (or appropriate inferences). Stars above the bars indicate significant effects.

Swinney (1979), and Tanenhaus et al. (1979). On the other hand, for intervals up to about $300 \mathrm{msec}$ (Experiments 2 and 3) or $333 \mathrm{msec}$ (Experiment 1), response times to appropriate and inappropriate associates are not significantly different, as others have found (e.g., Kintsch \& Mross, 1985; Onifer \& Swinney, 1981; Seidenberg et al., 1982; Swinney, 1979; Tanenhaus et al., 1979). The small context effects we observed in Experiment 2 (nonsignificant in the orthogonal comparisons for these short SOAs) thus can be overlooked: they did not recur in Experiment 1 or Experiment 3.

The data from Figure 4 were averaged to obtain the data presented in Figure 5, in order to show more clearly the time course of the effect of the discourse context on word identification. The three phases of sense activation, sense selection, and sense elaboration are clearly differentiated in this figure.

With respect to the priming of associates, the present results extend and confirm the pattern found in the literature. At prime-target SOAs from 200 to $333 \mathrm{msec}$, context-appropriate and context-inappropriate associates of homographs are identified with equal ease (Experiments 1,2 , and 3) and faster than unrelated control words (Experiment 3). From 400 to $1,500 \mathrm{msec}$, responses to context-appropriate associates are about $30 \mathrm{msec}$ faster than those to inappropriate associates. Thus, it takes about $350-400 \mathrm{msec}$ for the discourse context to settle on the appropriate meaning of a homograph and exclude the inappropriate one.

Glucksberg, Kreuz, and Rho (1986) recently argued that the facilitation of context-inappropriate associates, in the experimental paradigm used here and by others, is a consequence of backward associations and does not represent evidence for a lack of contextual constraint on lexical access. Although the present study was not designed to explore the role that backward associations might play, the evidence presented by Glucksberg et al. is far from compelling. Burgess, Seidenberg, and Tanenhaus (1986) presented a series of experiments questioning Glucksberg et al.'s experimental design and data interpretation. Even if one accepts the Glucksberg et al. data at face value, however, it may be that they examined the identification process at a late enough stage that postaccess decision processes occurred, a possibility that the authors themselves cannot entirely reject (p. 332).

The main results of the present series of experiments concern the pattern of priming for inference words. Topical inference words, if they are not associatively related to a prime word, show no priming at SOAs up to 500 msec, similar to results obtained by Tanenhaus et al. (1979) and Kintsch and Mross (1985). For most of the test sentences in Appendix A, it seems possible that subjects could infer the topic before reaching the priming word (with possible exceptions being items $4 a, 5 b, 11 a$, and 23a). But if such inferences were made, why did we observe no evidence of activation during the period right after the prime word but less than $1,000 \mathrm{msec}$ after its onset? It seems more parsimonious to assume that, rather than inferring the topic as soon as the essential information is available, subjects deferred such inferences until after the whole sentence was read. We know that much processing is done immediately (cf. evidence for the " im- 


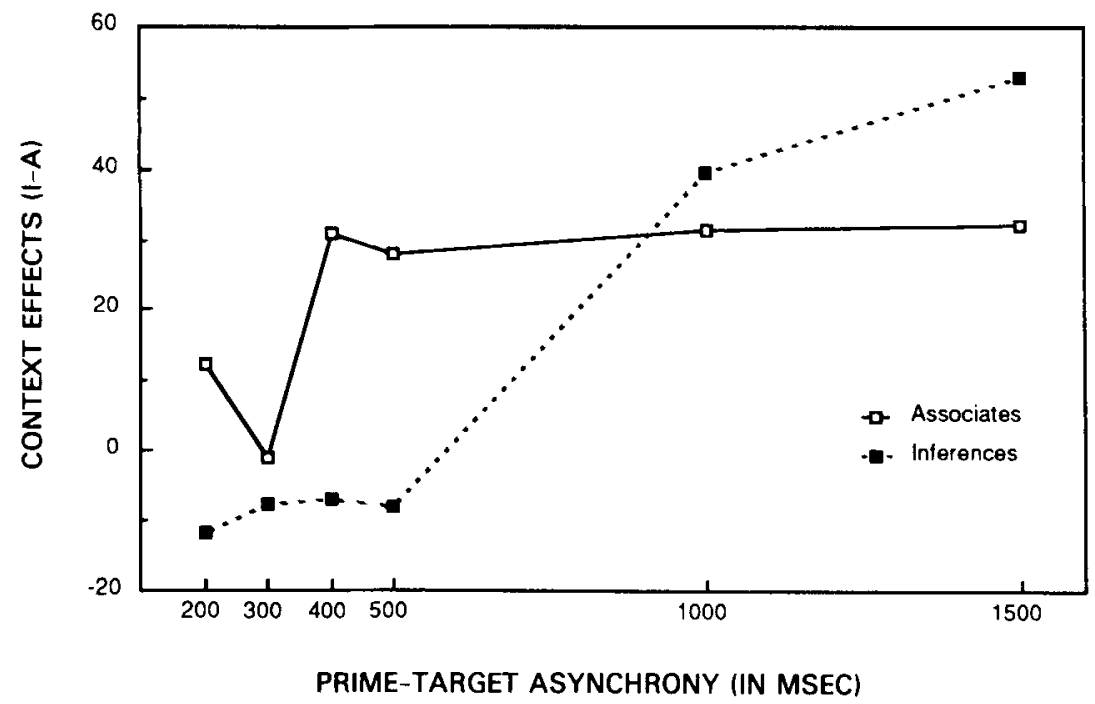

Figure 5. Time course of priming effects for associates and inferences averaged across all three experiments. Points represent the mean priming effect: response latencies for inappropriate associates (or inference controls) minus response latencies for appropriate associates (or appropriate inferences).

mediacy assumption" of Just \& Carpenter, 1980), but the present results suggest that this is not so for topical inferences (cf. McKoon \& Ratcliff, 1986). Of course, subjects did eventually infer sentence topics under the conditions of the present experiments so that, for SOAs of 1,000 and $1,500 \mathrm{msec}$, subjects responded to inference words about $40 \mathrm{msec}$ faster than to unrelated control words.

The present results are not relevant to the issue of whether such inferences are normally made during reading. They are relevant only to the issue of when they are made, if they are made at all. It is quite possible that inferences in the present study were made in response to an implied task demand: the long, empty SOA may have encouraged inference activity, especially because on $15 \%$ of the lexical decision trials, inference-related target words appeared. The question of whether topic inferences are made naturally, as an integral part of comprehension, as claimed by van Dijk and Kintsch (1983) and observed by Guindon and Kintsch (1984), is an important one, but is quite separate from the one asked here. We can only assert that, given the special task demands of the present experiments, topic inferences were not immediate, but were made reliably and required more than $500 \mathrm{msec}$ of processing time after the end of a sentence. Of course, such findings converge with those of the pilot study in which subjects demonstrated their ability to make these inferences when directly asked about the sentence topic and given as much time as needed to respond.

Related results were observed by Sharkey and Mitchell (1985), who found strong context effects for scriptal words in a lexical decision task after subjects read, at their own rate, a two-sentence script-based text. Presumably, by the time these subjects came to a lexical decision trial, they had sufficiently elaborated the text and had made the scriptal inference, thereby facilitating the identification of scriptal target words (as did our subjects in the 1,000and 1,500-msec conditions). Other results in accordance with these findings have been reported by Sharkey and Sharkey (1987). Script-appropriate phrases (e.g., "the tip" in a restaurant story) were read faster when compared with control phrases when the phrase appeared at the end of the final sentence of a story, but not when it appeared earlier. Scriptal elaborations require time, and occur at sentence wrap-up, somewhat like the thematic inferences in the present study. McKoon and Ratcliff (1986) investigated recognition responses to inference words after subjects read simple sentences, somewhat like the ones used in the present study. They, too, obtained evidence that subjects generally made the invited inferences. Their subjects, like those in the present study, had plenty of time to make these inferences. Thus, the present study is by no means alone in finding that subjects make elaborative inferences if they have enough time to do so. The important finding is that this kind of inferencing is not immediate, but appears to be part of the sentence wrapup processing.

This observation about when topic inferences are made completes the picture of how word meanings are constructed during discourse comprehension. The initial identification of word meanings is independent of the discourse context. To return to our mint example, we would say that, for SOAs up to about $350 \mathrm{msec}$, mint is both "candy" and "building." The first of these meanings is deactivated by $400 \mathrm{msec}$, however. To establish the complete contextual meaning of mint requires even more processing time, because the sentence topic is an important component thereof. Mint as a "building that withstands an earthquake" is decidedly something different 
from "where they make money and people come to gape." Such contextual elaboration of the meaning of mint apparently requires between 500 and $1,000 \mathrm{msec}$ of processing time. How this is done-what actually is activated in the reader's mind, how the selection is made, under what conditions which elaborations occur, and what the mechanisms are that produce these elaborations-are questions beyond the scope of this paper (Kintsch, 1988). All we can do here is to show that this process of construction begins conservatively with a context-free, bottom-up semantic interpretation of the word, which is quickly followed by the contextual integration of the word into the discourse context. Meaning is a construction that takes time, quite appreciable time.

\section{REFERENCES}

Barclay, J. R., Bransford, J., Franks, J., McCarrell, N., NitsCH, K. (1974). Comprehension and semantic flexibility. Journal of Verbal Learning \& Verbal Behavior, 13, 471-481.

Burgess, C., Seidenberg, M., \& Tanenhaus, M. K. (1986, November). Nonword interference and lexical ambiguity resolution. Paper presented at the meeting of the Psychonomic Society, New Orleans.

Cramer, P. (1970). A study of homographs. In L. Postman \& G. Keppel (Eds.), Norms of word association (pp. 361-382). New York: Academic Press.

Fischler, I. \& Goodman, G. O. (1978). Latency of associative activation in memory. Journal of Experimental Psychology: Human Perception \& Performance, 4, 455-470.

Galambos, J. A. (1982). Normative studies of six characteristics of our knowledge of common activities (Cognitive Science Tech. Rep. 14). New Haven, CT: Yale University.

Glucksberg, S., Kreuz, R. J., \& Rho, S. (1986). Context can constrain lexical access: Implications for models of language comprehension. Joumal of Experimental Psychology: Leaming, Memory, \& Cognition, 12, 323-335.

GreEnSPan, S. L. (1986). Semantic flexibility and referential specificity of concrete nouns. Journal of Memory \& Language, 25, 539-557.

GuINDON, R., \& KINTsCH, W. (1984). Priming macropropositions: Evidence for the primacy of macropropositions in the memory for text. Journal of Verbal Learning \& Verbal Behavior, 23, 508-518.

Just, M. A., \& CARPENTER, P. A. (1980). A theory of reading: From eye fixation to comprehension. Psychological Review, 87, 329-354.

KINTSCH, W. (1988). The role of knowledge in discourse comprehension: A construction-integration model. Psychological Review, 95, 163-182.

KINTSCH, W. (in press). The representation of knowledge and the use of knowledge in discourse comprehension. In C. Graumann \& R. Dietrich (Eds.), Language in the social context. New York: Springer.

KINTSCH, W., \& Mross, E. F. (1985). Context effects in word identification. Joumal of Memory \& Language, 24, 336-349.

KuČera, H., \& FranCIS, W. N. (1967). Computational analysis of present-day American English. Providence, RI: Brown University Press.

McKoon, G., \& RatclifF, R. (1986). Inferences about predictable events. Joumal of Experimental Psychology: Learning, Memory, \& Cognition, 12, 82-91.

ONIFER, W., \& SWINNEY, D. A. (1981). Accessing lexical ambiguities during sentence comprehension: Effects of frequency of meaning and contextual bias. Memory \& Cognition, 9, 225-236.

Seidenberg, M. S., Tanenhaus, M. K., Leiman, J. M., Bienkowski, M. (1982). Automatic access of the meaning of ambiguous words in context: Some limitations of knowledge-based processing. Cognitive Psychology, 14, 489-537.

Sharkey, N. E., Mitchell, D. C. (1985). Word recognition in a functional context. Journal of Memory \& Language, 24, 253-270.

Sharkey, N. E., Sharkey, A. J. C. (1987). What is the point of integration? The loci of knowledge-based facilitation in sentence processing. Journal of Memory \& Language, 26, 255-276.

Simpson, G. B. (1984). Lexical ambiguity and its role in models of word recognition. Psychological Bulletin, 96, 316-340.

SWINNEY, D. A. (1979). Lexical access during sentence comprehension: (Re)consideration of context effects. Journal of Verbal Learning \& Verbal Behavior, 18, 645-659.

TAFT, M. (1982). An alternative to grapheme-phoneme conversion rules? Memory \& Cognition, 10, 465-474.

Tanenhaus, M. K., Leiman, J. M., \& Seidenberg, M. S. (1979). Evidence for multiple stages in the processing of ambiguous words in syntactic contexts. Journal of Verbal Learning \& Verbal Behavior, $18,427-440$.

TILL, R. E. (1977). Sentence memory prompted with inferential recall cues. Journal of Experimental Psychology: Human Learning \& Memory, 3, 129-141.

TILL, R. E., \& WALSH, D. A. (1980). Encoding and retrieval factors in adult memory for implicational sentences. Journal of Verbal Leaming \& Verbal Behavior, 19, 1-16.

VAN DIJK, T., \& KINTSCH, W. (1983). Strategies of discourse comprehension. New York: Academic Press.

\section{NOTES}

1. We have chosen an example in which the two meanings of the homograph are known to be about equally dominant (e.g., Cramer, 1970); Simpson (1984) discussed the asymmetric case in depth.

2. In this pilot work, inference priming was examined by comparing the latencies for a test word (presented at a 1,200-msec SOA) following an appropriate discourse or an altered, inappropriate discourse. For example, latencies for suicide were similar after "The millionaire jumped from the window" and "The millionaire approached the bank window."

3. Priming effects observed here (i.e., latency differences between appropriate and inappropriate items) were not strongly correlated with normative response probabilities. Across associate items, we found a significant correlation between priming magnitude and response probability only at the 1,500 -msec SOA $[r(54)=.32]$. Across inference items, we found a marginal correlaton between priming magnitude and response probability at the 1,500 -msec SOA $[r(54)=.23, p<.09]$; the only significant correlation at shorter SOAs was an uninterpretable negative one $[r(54)=-.27$, at the $200-\mathrm{msec}$ SOA]

\section{APPENDIX A}

Critical Paragraphs with Associate and Inference Test Words

\begin{tabular}{llll}
\hline \multicolumn{1}{c}{ Paragraph } & Associate & Inference \\
\hline 1a. & $\begin{array}{l}\text { The townspeople were amazed to find that all the } \\
\text { buildings had collapsed except the mint. Obvi- } \\
\text { ously, it had been built to withstand natural dis- } \\
\text { asters. }\end{array}$ & & \\
\end{tabular}

1b. Thinking of the amount of garlic in his dinner, the guest asked for a mint. He soon felt more comfortable socializing with the others. 


Paragraph Associate Inference

2a. For the third time, the worried player swung but missed the ball. He knew what the coach would say.

bat out meet people.

3a. The jockey was happy to receive the trophy. However, he said the secret was his use of a new kind of harness and bit.

3b. All afternoon the chef monitored the food preparations for the party. He tasted the soup, then added a little bit.

4a. The doctor became very nervous as he watched the patient's pupils. He had seen this kind of problem only once or twice before.

4b. The thumbtack was carefully positioned on the chair by one of the pupils. Everyone watched as the newcomer went to his assigned desk.

5a. When the boy was sent to bed without supper, the mother worried that her husband was too rash. He had not asked for the boy's side of the story.

5b. The hiker reached in his pack when he realized he had a rash. There must be something that would stop the itch.

6a. The lawyer read the document to the entire group. Then the witness signed at the bottom and filled in the dates.

6b. Despite the storm, the lightning and the 50 -foot waves, a few survivors held tightly to the mast. Eventually they reached a desert island and began to feast on dates.

7a. Round after round, the visitor tried to find his opponent's weakness. When the fencing instructor blew his whistle, the visitor grudgingly lowered his foil.

7b. The servant lit the fire and then prepared the meat. He seasoned it and wrapped it in foil.

8a. The millionaire jumped from the window when he heard about the new rate of interest. His entire fortune was at stake.

8b. The husband was afraid that his jealous wife would discover his new interest. He kept looking for clever ways to account for his time.

9a. Jim became the first to win the contest from his club. He viewed the challenge as a patriotic duty

9b. The caveman had been searching so long that when he finally came upon a small animal, he was not able to swing his club. He was frustrated, to say the least. dance marriage

horse race

piece salt

eye sick

student prank

harsh punishment

hives medicine

year

court

fruit

shipwreck

sword

defeat

tin

barbecue

money suicide

hobby affair

group proud

hit

tired 


\begin{tabular}{l} 
Paragraph \\
\hline 10a. The students wrote as fast as they could while the \\
professor covered one board and went on to a sec- \\
ond. It seemed that every class period was like \\
this.
\end{tabular}

10b. The master was ready and moved the piece in less than a second. His opponent would have to try a new strategy.

11a. When the maid turned away from the laundry, the baby grabbed the iron. Later that day, the maid started looking for a new job.

11b. The worker was struck by a gigantic, falling chunk of iron. Everyone was seriously upset by the accident.

12a. The waiter left quickly as he saw the angry customer tear up the bill. He did not want to risk getting in a fight.

12b. The parents helped the little boy toss food through the fence in the direction of the animal's bill.

Then they all walked on to see the other animals.

13a. The host raised his glass in honor of the sage. His timeless advice was helpful to all.

13b. The buldings were run down, the windows were boarded up, and the only traffic was the blowing tumbleweed and sage. Still, one could sense the importance the town once had.

14a. The gardener pulled the hose around to the holes in the yard. Perhaps the water would solve his problem with the mole.

14b. The patient sensed that this was not a routine visit. The doctor hinted that there was serious reason to remove the mole.

15a. The fighter pilot scanned the waters until he located it. All that could be seen above water was the tip.

15b. The waitress smiled and said she would get off work soon. The young man decided to wait and left a big tip.

16a. The architect displayed his final version of the plans. He had used all the available information on file.

16b. The old woman awoke to a sound from downstairs. She reached in her purse but found only a file.

17a. The audience stood and continued to clap loudly after the last refrain. The performance was easily the best of the concert season.

17b. Dave played his chips quickly and went for more; he seemed unable to refrain. His whole life revolved around the game.

18a. The rabbi looked for something to use in putting up his announcement. Finally, he used his shoe to tack it to the door of the temple.

Associate Inference

first

notes

minute chess

clothes burn

steel dead

check fear

duck zoo

wise toast

brush deserted

ground drown

face cancer

end submarine

money date

papers blueprint

nail

burglar

song encore

stop gamble

church hammer 


Paragraph
18b. Mike rehearsed his moves mentally. At the signal,
he planned to go for his opponent's left ear and
temple.

Associate

Inference

19a. The sparrow loved to compete with the others. But no matter how hard he worked, he could not keep up with the swallow.

head boxing

bird flying

19b. The big moment arrived and the boy was very excited. He blew out the candles and then bit into more cake than he could possibly swallow.

20a. The sailors felt that they had no choice. They could no longer tolerate a captain so mean.

20b. The proofreader checked each chapter. Then he added some numbers, and filled in the mean.

21a. The parents worried about their son's way of life. His troubles with the police were made worse by his temper and stubborn will.

21b. Several policies were found and processed. The relatives received the money from the company long before the settlement of the will.

$\begin{array}{ll}\text { gulp } & \text { birthday } \\ \text { cruel } & \text { mutiny } \\ \text { average } & \text { correct } \\ \text { mind } & \text { jail }\end{array}$

testament insurance

22a. The little girl was very happy with the new doll from her grandmother. She reached up to hug her and give her a little smack.

kiss

love

22b. Danny had a lot to learn about riding bicycles. Going too fast and looking the other way, he rode into the wall with a smack.

\begin{tabular}{ll} 
hit & pain \\
fly & vampire \\
ball & broken \\
soft & fall \\
leg & miracle \\
light & England \\
ceiling & repair \\
boy & message \\
church & sleep \\
& test \\
\hline weight & \\
& \\
\hline
\end{tabular}

It was dark as the young woman passed the graveyard. Having seen too many movies, she was afraid of the sudden appearance of a bat.

23b. The teammates heard the loud crack. That was the last time anyone would be able to use that bat.

24a. After desparately holding the rope for hours, the climber felt his arms begin to go limp. Still, he had hopes that he would be rescued.

24b. After touching Christ, the beggar found that he no longer walked with a limp. He had been rewarded for his faith.

25a. Everyone drove on the left side. At night, they seemed quite courteous and used only the low beam.

25b. The restaurant manager started to panic. He had looked up and noticed a huge crack in the beam.

26a. The old man sat with his head down and did not hear a word of the sermon during mass.

Nevertheless, he felt better after the service.

26b. The chemistry student knew that this was not a good time to forget how to calculate volume and mass. Again, she tried to recall the formulas.

27a. The scribbling on the paper was hard to read but was apparently of great importance. It was carried to the king by a young page. 
APPENDIX A (Continued)

Paragraph

Associate

Inference

27b. He rarely had to perform a job of this sort. Thus, the mechanic followed carefully the directions on each page.

book car

28a. The evidence was very convincing. Although the judge thought it was useless, he agreed to review the case.

history guilty

28b. The fraternity party finally came to an end. There were several examples of what happens when one tries to consume a case.

box drunk

(Manuscript received April 27, 1987;

revision accepted for publication December 3, 1987.) 